\title{
Qualitative and Quantitative Chemical Investigation of Orthopedic Alloys by Combining Wet Digestion, Spectroanalytical Methods and Direct Solid Analysis
}

\author{
Caio M. Figueiredo, Jeyne P. Castro, Marco A. Sperança, Lucimar L. Fialho, \\ Joaquim A. Nóbrega and Edenir R. Pereira-Filho* \\ Grupo de Análise Instrumental Aplicada (GAIA), Departamento de Química, \\ Universidade Federal de São Carlos, P.O. Box 676, 13565-905 São Carlos-SP, Brazil
}

\begin{abstract}
In this study, two laser-based techniques, laser-induced breakdown spectroscopy (LIBS) and laser ablation-inductively coupled plasma-mass spectrometry (LA-ICP-MS) were used for analytical signal evaluation of $\mathrm{Ti}, \mathrm{Al}$, and $\mathrm{V}$ and investigation of possible harmful elements eventually present as minor elements in Ti alloys. Due to the lack of certified reference materials, samples were also analyzed by wavelength dispersive X-ray fluorescence (WDXRF) and inductively coupled plasma optical emission spectrometry (ICP OES) after microwave-assisted digestion. To maximize the efficiency of LIBS and LA-ICP-MS, operational conditions were adjusted aiming to find optimal analytical performance. LIBS showed several Ti emission lines and few signals for $\mathrm{Al}$ and V. LA-ICP-MS was able to detect all three major constituents. For quantitative analysis, the correlation of intensity signals from LIBS analysis with reference values obtained by ICP OES was not successful, showing that there are still difficulties for quantification using solid samples. Measurements using ICP OES showed that additionally to major constituents, only Fe was present in concentrations around $0.2 \%$. Analysis by WDXRF confirmed the presence of Fe. Results using both methods, i.e., ICP OES and WDXRF, were in good agreement.
\end{abstract} LIBS

Keywords: orthopedic alloys, direct solid analysis, XRF, ICP OES, ICP-MS, laser ablation,

\section{Introduction}

Several technologies in the area of orthopedic implants have been developed to improve the quality of life. ${ }^{1}$ The prostheses are mainly used to replace or repair damaged limbs or hard tissues, such as bones. ${ }^{2}$ The Brazilian Health Regulatory Agency (ANVISA) ${ }^{3}$ defines orthopedic implants as any medical product designed to be totally introduced in the human body by surgery. Materials for implants must follow some requirements, such as biomechanics compatibility, resistance to mechanical impact and corrosion, so it can remain for a long time inside the human body without breaking or releasing harmful elements. ${ }^{4}$

Numerous materials are used for implants, such as ceramics, polymers and alloys. In this study, one type of metallic material, the ASTM-AF-136 Ti alloy (Ti-6Al-4V), ${ }^{5}$ whose nominal composition is $6 \%$ of $\mathrm{Al}, 4 \%$ of $\mathrm{V}$ and $\mathrm{Ti}$ (balance) was searched. Geetha et al. ${ }^{1}$ discussed about

*e-mail: erpf@ufscar.br the qualities of many metals based orthopedic prostheses and it was concluded about the superiority of the Ti-based orthopedic alloys taking into account their corrosion and mechanical resistance and also better biocompatibility.

If concentrations are out of target proportions, chemical and mechanical characteristics of the material are compromised and they are more affected by failures. Also, implants are prone to leaks due to corrosion, releasing potential harmful elements into the body. Many diseases are associated with high concentrations of metallic ions, for example, $\mathrm{Al}^{\mathrm{III}}, \mathrm{V}^{\mathrm{III}}$ and $\mathrm{V}^{\mathrm{V}}$, eventually present in the alloys used for implants. ${ }^{6}$ Aluminum is associated with the development of neural disturbs, such as Alzheimer and amyotrophic lateral sclerosis (ALS) ${ }^{6-8}$ whereas V is associated with carcinogenetic effects. ${ }^{8}$ Therefore, it is important to develop analytical methods for chemical analysis of orthopedic alloys to evaluate concentrations of each element, avoiding mechanical problems and diseases after the implant. ${ }^{8}$

Due to the high resistance of corrosion of Ti alloys, instrumental methods not requiring sample preparation 
would be preferable. Therefore, two laser-based techniques: laser-induced breakdown spectroscopy (LIBS) and laser ablation-inductively coupled plasma-mass spectrometry (LA-ICP-MS) were investigated. Wavelength dispersive $\mathrm{X}$-ray fluorescence (WDXRF) was also used for results comparison.

LIBS consists in a laser pulse reaching the surface of a material releasing a high energy that is able to ablate a small quantity (from ng to $\mu \mathrm{g}$ range) of mass of the sample. Due to the high temperature caused by the laser pulse, the elements presented in the sample are atomized, ionized and excited to a higher energy level creating a plasma. When these elements return to the original energy level they emit photons in specific wavelengths that are collected by an optical fiber and registered by a spectrometer. After that, a full spectrum is recorded at a computer. ${ }^{9}$ Advantages of LIBS are: direct analysis, requiring low or none sample preparation, the simplicity of instrumental arrangement, the possibility to direct analysis of hard materials (gorilla glasses, ceramics, alloys, among others), radioactive and hazardous substances and its non-destructive character. Limitations of LIBS are its relatively poor limits of detection, poor precision and the lack of reference materials with several matrices and with analytes certified concentrations when working with sample masses of $\mu \mathrm{g} .{ }^{10}$ Normally, in the case of solid reference materials the certified values are guaranteed when masses of $\mathrm{mg}$ range (around $100 \mathrm{mg}$ ) are used.

The other laser technique used was LA-ICP-MS. It consists in the ablation of the solid sample, forming suspended particles that are carried out towards argon plasma. In ICP-MS, suspended particles are atomized and ionized. Ions are transported and separated through a mass spectrometer and reaches a detector creating a mass/charge spectrum. The LA-ICP-MS presents high sensitivity and capability to detect elements in the $\mu \mathrm{g} \mathrm{kg}^{-1}$ concentration range. However, it demands reference materials with certified values when sample masses in the $\mu$ g range are used. ${ }^{11}$

In the scientific literature, it was not found papers related to LIBS and orthopedic implants analysis focusing Ti determination. The majority of the papers are related to laser setup physical parameters and signal standardization or normalization. Castro and Pereira-Filho ${ }^{12}$ for instance used LIBS for several alloys analysis (including $\mathrm{Ni}, \mathrm{Cr}$ and Ti alloys) and twelve normalization modes were tested combined with univariate and multivariate calibration strategies. Ni et al. ${ }^{13}$ applied LIBS spectral normalization in Ti alloys analysis and the focus was instrumental studies. Valenzuela et al..$^{14}$ investigated the use of femtosecond laser ablation for analysis of steels and Ti alloys. In the case of
LA-ICP-MS no paper was found related to Ti determination in Ti alloys. The study proposed by Sajnóg et al. ${ }^{15}$ used LA-ICP-MS for Ti, $\mathrm{Al}$ and $\mathrm{V}$ determination in soft tissues after placing dental implants. As can be observed, the literature combining laser based techniques and orthopedic implants analysis is rare. For these two laser techniques, chemometric tools were applied for optimization of instrument conditions, treatment and data interpretation. This strategy improved the quality of information and saved time and resources. ${ }^{16}$

WDXRF has been used as an analytical method for about one century ${ }^{17}$ and it is consolidated in several areas, such as soil and plant analysis. ${ }^{18}$ It consists in the excitation of the sample with monoenergetic photons (X-ray fluorescence), creating a spectral emission. Its advantages are the good sensitivity, being able to detect elements in the $\mathrm{mg} \mathrm{kg}^{-1}$ range, its non-destructive character and, in several cases, does not require sample preparation. ${ }^{17}$

These three techniques, despite well studied, are still not consolidated for the analysis of orthopedic alloys. Therefore, samples were also analyzed by inductively coupled plasma optical emission spectrometry (ICP OES) after microwave-assisted digestion for establishing reference values for concentrations of samples constituents.

ICP OES is based on atomic emission by excited atoms and ions. Generally, liquid sample is transported towards argon plasma and excited by plasma, emitting radiation that is captured by the detectors and generates an emission spectrum. ${ }^{19}$ This method requires sample preparation that may be difficult, but also presents advantages, such as good sensitivity, reliable determination of elements in the $\mathrm{m} \mathrm{kg}^{-1}$ or $\mu \mathrm{g} \mathrm{kg}^{-1}$ ranges and high precision. ${ }^{19}$

The goal of this study was to investigate the analytical capability of LIBS, LA-ICP-MS, and WDXRF, and compare these results with those obtained by ICP OES, thus highlighting advantages and shortcomings that should be overcome.

Another goal of this study was to correlate intensities acquired by laser techniques with reference values, which were obtained by ICP OES after microwave-assisted digestion. This last goal was an attempt to obtain a calibration curve using solid samples.

\section{Experimental}

\section{Sample preparation}

Nine bars of Ti alloy (Ti-6Al-4V) obtained from different producers were provided by the Center for Characterization and Development of Materials (CCDM, UFSCar, Brazil). Using a lathe, samples were fixed and cut 
with a fast steel drill at low rotation. The metallic particles obtained were used for microwave-assisted digestion. Also resulting solid samples with around $10 \mathrm{~mm}$ diameter and $5 \mathrm{~mm}$ thickness were analyzed by both LIBS and LA-ICP-MS.

\section{Reagents}

Standard solutions used for calibration of ICP OES were prepared with ultrapure water obtained from a Milli-Q purification system (Millipore Corp., Bedford, MA, USA). They were prepared by subsequent dilutions of $1000 \mathrm{mg} \mathrm{L}^{-1}$ stock standards solutions (Titrisol-Merck, Darmstadt, Germany) of Ti, Al, V (the three major constituents) and $\mathrm{Cd}, \mathrm{Co}, \mathrm{Cr}, \mathrm{Cu}, \mathrm{Fe}, \mathrm{Mn}, \mathrm{Mo}, \mathrm{Ni}, \mathrm{Pb}, \mathrm{Sn}$ and $\mathrm{Zn}$, eventually present as minor constituents or contaminants.

For microwave-assisted digestion, concentrated $\mathrm{H}_{2} \mathrm{SO}_{4}$ (Synth, Diadema, São Paulo, Brazil) was used after proper dilution.

\section{Microwave-assisted digestion and ICP OES determination}

A mass of $50 \mathrm{mg}$ of each alloy was weighed using an analytical balance (model AY 220, Shimadzu, Kyoto, Japan). Samples were microwave-assisted digested using $5.0 \mathrm{~mL}$ of $25 \% \mathrm{v} / \mathrm{v} \mathrm{H}_{2} \mathrm{SO}_{4}$ solution in a Speedwave 4 microwave oven equipped with DAP-30+ PTFE (polytetrafluoroethylene) vessels with internal volume of $30 \mathrm{~mL}$ (Berghof, Eningen, Germany). A heating program with 3 steps was used: (i) $155^{\circ} \mathrm{C}(2 \mathrm{~min}$ ramp and 5 min holding at $80 \%$ of the total power), (ii) $200{ }^{\circ} \mathrm{C}$ (3 min ramp and $10 \mathrm{~min}$ holding at $80 \%$ of the total power), and (iii) $220{ }^{\circ} \mathrm{C}$ (3 min ramp and $10 \mathrm{~min}$ holding at $90 \%$ of the total power). The maximum operational pressure for this type of vessel (DAP-30+) is 80 bar and the maximum radiation power for this oven is $1450 \mathrm{~W}$.

The digests were diluted 5,000-fold to determine minor constituents/contaminants eventually present $(\mathrm{Cd}$, $\mathrm{Co}, \mathrm{Cr}, \mathrm{Cu}, \mathrm{Fe}, \mathrm{Mn}, \mathrm{Mo}, \mathrm{Ni}, \mathrm{Pb}, \mathrm{Sn}$ and $\mathrm{Zn}$ ) and then it was performed a further dilution of 100,000-fold for determining major constituents ( $\mathrm{Ti}, \mathrm{Al}$ and $\mathrm{V}$ ) of the alloys.

The calibration curve for each analyte was obtained using 10 aqueous standard solutions containing: 0, 0.1, $0.25,0.5,1,2.5,5,10,20$ and $30 \mathrm{mg} \mathrm{L}^{-1}$. These solutions were prepared in diluted $\mathrm{H}_{2} \mathrm{SO}_{4}$ medium, i.e., around $10^{-5} \mathrm{~mol} \mathrm{~L}^{-1}$.

The ICP OES equipment used was an iCAP 6000 from Thermo (Thermo Fisher Scientific, Madison, WI, USA) and measurements were performed using authentic triplicates $(n=3)$. The set instrumental parameters for measurements were: $1.15 \mathrm{~kW}$ of radio frequency power, plasma gas (Ar) flow rate was $12.0 \mathrm{~L} \mathrm{~min}^{-1}$, auxiliary gas (Ar) flow rate was $0.5 \mathrm{~L} \mathrm{~min}^{-1}$, nebulizer gas (Ar) flow rate was $0.70 \mathrm{~L} \mathrm{~min}^{-1}$ and sample flow rate was $1.1 \mathrm{~mL} \mathrm{~min}^{-1}$. One emission line of each analyte was monitored using axial viewing, and spectrum environment was verified for emission interferences. Table 1 shows elements and emission lines monitored.

Table 1. Emission lines monitored in ICP OES measurements

\begin{tabular}{lccc}
\hline Analyte & $\begin{array}{c}\text { Emission } \\
\text { line } / \mathrm{nm}\end{array}$ & Analyte & $\begin{array}{c}\text { Emission } \\
\text { line } / \mathrm{nm}\end{array}$ \\
\hline $\mathrm{Ti}$ & II 334.9 & $\mathrm{Fe}$ & II 259.9 \\
$\mathrm{Al}$ & I 396.1 & Mn & II 260.5 \\
$\mathrm{~V}$ & II 292.4 & Mo & II 204.5 \\
$\mathrm{Cd}$ & I 228.8 & $\mathrm{Ni}$ & II 231.6 \\
$\mathrm{Co}$ & II 228.6 & $\mathrm{~Pb}$ & II 182.2 \\
$\mathrm{Cr}$ & I 238.5 & $\mathrm{Sn}$ & I 242.9 \\
$\mathrm{Cu}$ & I 324.7 & $\mathrm{Zn}$ & II 206.2 \\
\hline
\end{tabular}

at: atomic line; II: ionic line. ICP OES: inductively coupled plasma optical emission spectrometry.

\section{WDXRF: optimization and analysis}

The WDXRF equipment used was an ARL Perform' $X$ from Thermo (Thermo Fisher Scientific, Madison, WI, USA) and the build-in software used for quantitative analysis was the UniQuant ${ }^{\circledR}$. Samples were the same ones used in LIBS and LA-ICP-MS experiments and no pretreatment was performed.

Two sets of experiments were performed. The first one aimed qualitative analysis of the three major constituents and Fe. Instrumental parameters are shown in Table 2. The applied voltage and current were fixed in $50 \mathrm{kV}$ and $50 \mathrm{~mA}$, respectively. In all cases the count time was kept in $5 \mathrm{~s}$.

Table 2. Instrumental parameters for WDXRF analysis

\begin{tabular}{lccc}
\hline Element & Crystal & $\begin{array}{c}\text { Wavelength } \\
\text { increment / }\end{array}$ & $\begin{array}{c}\text { Collimator / } \\
\mathrm{mm}\end{array}$ \\
\hline $\mathrm{Ti}$ & LiF200 & 0.1 & 0.4 \\
$\mathrm{Al}$ & $\mathrm{AX03}$ & 0.05 & 0.4 \\
$\mathrm{~V}$ & $\mathrm{AX03}$ & 0.025 & 0.15 \\
$\mathrm{Fe}$ & $\mathrm{LiF} 200$ & 0.1 & 0.4 \\
\hline
\end{tabular}

WDXRF: wavelength dispersive X-ray fluorescence.

The second experiment used the build-in software Uniquant ${ }^{\circledR}$ for semi-quantitative analysis using fundamental parameters. This software automatically scan samples for all metals and choose the best instrumental parameters. 
Additionally, using the data obtained by ICP OES as reference values, calibration curves were built with the signals obtained by WDXRF analysis to quantify Ti, Al, V and Fe. Five samples were used to build calibration curves and 4 samples were used for validation.

\section{LIBS: optimization and analysis}

The LIBS system used was the model J200 of Applied Spectra (Fremont, CA, USA) thoroughly detailed elsewhere. ${ }^{20,21}$ The optimization of instrumental conditions was carried out by performing 15 experiments in one sample and by simultaneously monitoring the three major elements. Laser pulse energy (30-80 mJ), delay time $(0-2 \mu \mathrm{s})$, and spot size $(50-150 \mu \mathrm{m})$ were varied. It was monitored the most intense emission lines of each element (Ti II $308.8 \mathrm{~nm}, \mathrm{Al}$ I $394.4 \mathrm{~nm}$ and V II $437.9 \mathrm{~nm}$, where I is the atomic line and II the ionic line). Three responses were measured: signal-to-background ratio, area, and height of each signal. Experimental data were organized according to a Doehlert design ${ }^{22}$ to calculate regression models for establishing the most adequate experimental condition. The software MATLAB ${ }^{\otimes 23}$ was applied for calculations and Microsoft Excel $^{\circledR}$ was used for matrices organization.

\section{LA-ICP-MS: optimization and analysis}

The laser ablation system used was a Teledyne Photo Machines LSX-213 G2+ model (Teledyne CETAC Technologies, Omaha, NE, USA) and the ICP-MS was an iCAP-Q (Thermo Fisher Scientific, Madison, WI, USA). The laser is a Nd-YAG emitting in $213 \mathrm{~nm}$. Fractional factorial design with 6 variables, i.e., helium and argon flow rates, spot size, frequency, laser pulse energy and speed, was adopted for optimization, and one sample was studied. The responses analyzed were height and area of the signals. Again, data were treated using $\mathrm{MATLAB}^{\circledR 23}$ and Microsoft Excel ${ }^{\circledR}$. A total of 43 isotopes were monitored based on mass-to-charge ratios measurements: ${ }^{12} \mathrm{C},{ }^{13} \mathrm{C}$, ${ }^{27} \mathrm{Al},{ }^{46} \mathrm{Ti},{ }^{47} \mathrm{Ti},{ }^{48} \mathrm{Ti},{ }^{49} \mathrm{Ti},{ }^{50} \mathrm{Ti},{ }^{50} \mathrm{Cr},{ }^{50} \mathrm{~V},{ }^{51} \mathrm{~V},{ }^{52} \mathrm{Cr},{ }^{55} \mathrm{Mn},{ }^{56} \mathrm{Fe}$, ${ }^{57} \mathrm{Fe},{ }^{58} \mathrm{Fe},{ }^{59} \mathrm{Co},{ }^{60} \mathrm{Ni},{ }^{53} \mathrm{Cr},{ }^{61} \mathrm{Ni},{ }^{62} \mathrm{Ni},{ }^{63} \mathrm{Cu},{ }^{64} \mathrm{Ni},{ }^{64} \mathrm{Zn},{ }^{65} \mathrm{Cu}$, ${ }^{66} \mathrm{Zn},{ }^{67} \mathrm{Zn},{ }^{68} \mathrm{Zn},{ }^{70} \mathrm{Zn},{ }^{92} \mathrm{Mo},{ }^{94} \mathrm{Mo},{ }^{95} \mathrm{Mo},{ }^{9} \mathrm{Mo},{ }^{97} \mathrm{Mo},{ }^{98} \mathrm{Mo}$, ${ }^{100} \mathrm{Mo},{ }^{111} \mathrm{Cd},{ }^{112} \mathrm{Cd},{ }^{113} \mathrm{Cd},{ }^{114} \mathrm{Cd},{ }^{206} \mathrm{~Pb},{ }^{207} \mathrm{~Pb}$, and ${ }^{208} \mathrm{~Pb}$.

\section{Results and Discussion}

\section{Reference values}

Microwave-assisted digestion and ICP OES determination Titanium and its alloys are often digested by mixing hydrofluoric and nitric acids. ${ }^{24}$ Due to the high risk of handling, it was opted for a safer acid solution. Thus, diluted sulfuric acid was used to digest Ti alloys. To minimize the use of acid, different concentrations were tested, varying from 10 to $75 \% \mathrm{v} / \mathrm{v}$ of $\mathrm{H}_{2} \mathrm{SO}_{4}$. Heating program was applied as before mentioned (see Experimental section, Microwave-assisted digestion and ICP OES determination sub-section). According to visual observation, the minimum sulfuric acid concentration that digested all solid particles was $25 \% \mathrm{v} / \mathrm{v} \mathrm{H}_{2} \mathrm{SO}_{4}$.

Cadmium, $\mathrm{Co}, \mathrm{Cr}, \mathrm{Cu}, \mathrm{Mn}, \mathrm{Mo}, \mathrm{Ni}, \mathrm{Pb}, \mathrm{Sn}$ and $\mathrm{Zn}$ in respective emission lines monitored (see Table 1) presented limits of detection from 0.01 to $0.2 \mathrm{mg} \mathrm{kg}^{-1}$. Their concentrations were below their LODs, therefore, it is possible to affirm that these elements were not detected in the samples as harmful elements. The LODs (\%) of major constituents and the only minor constituent found in samples were: $0.07(\mathrm{Ti}), 0.04(\mathrm{Al}), 0.04(\mathrm{~V})$ and $0.08(\mathrm{Fe})$. These LODs were obtained after 10 measurements of blank solutions..$^{25}$ The determined concentrations used as reference values are shown in Table 3. These reference values may be seen at least as indicative concentrations and they are important for further calculations when applying LIBS and LA-ICP-MS.

Table 3. $\mathrm{Ti}, \mathrm{Al}, \mathrm{V}$ and $\mathrm{Fe}$ reference concentrations (mean \pm standard deviation $(\mathrm{SD}), \mathrm{n}=3$ ) obtained after microwave-assisted digestion and ICP OES determination

\begin{tabular}{lcccc}
\hline \multirow{2}{*}{ Sample } & \multicolumn{4}{c}{ Analyte concentration /\% } \\
\cline { 2 - 5 } & $\mathrm{Ti}$ & $\mathrm{Al}$ & $\mathrm{V}$ & $\mathrm{Fe}$ \\
\hline 1 & $92 \pm 1$ & $5.2 \pm 0.2$ & $4.1 \pm 0.2$ & $0.22 \pm 0.01$ \\
2 & $96 \pm 11$ & $5.5 \pm 0.6$ & $4.4 \pm 0.5$ & $0.207 \pm 0.003$ \\
3 & $113 \pm 8$ & $6.5 \pm 0.4$ & $5.1 \pm 0.4$ & $0.21 \pm 0.02$ \\
4 & $101 \pm 8$ & $5.7 \pm 0.5$ & $4.4 \pm 0.6$ & $0.107 \pm 0.008$ \\
5 & $91 \pm 1$ & $5.2 \pm 0.1$ & $3.9 \pm 0.1$ & $0.21 \pm 0.02$ \\
6 & $92 \pm 5$ & $5.2 \pm 0.3$ & $3.9 \pm 0.3$ & $0.11 \pm 0.01$ \\
7 & $94 \pm 1$ & $5.3 \pm 0.1$ & $4.0 \pm 0.2$ & $0.185 \pm 0.006$ \\
8 & $94 \pm 9$ & $5.3 \pm 0.5$ & $3.9 \pm 0.3$ & $0.106 \pm 0.004$ \\
9 & $79 \pm 14$ & $5.3 \pm 0.4$ & $3.8 \pm 0.2$ & $0.102 \pm 0.009$ \\
Overall & $95 \pm 24$ & $5.5 \pm 2$ & $4.2 \pm 1$ & $0.160 \pm 0.04$ \\
mean \pm SD & & & & \\
\hline
\end{tabular}

ICP OES: inductively coupled plasma optical emission spectrometry.

As it can be observed, Ti concentrations varied from 79 to $113 \%(\overline{\mathrm{x}}=95 \%)$. Aluminum and $\mathrm{V}$ concentrations ranged from 5 to $6 \%(\bar{x}=5.5 \%)$ and from 3 to $4 \%(\bar{x}=4.2 \%)$, respectively. Iron concentrations were lower than $0.3 \%$ in all samples. The nominal proportions of the alloy were $90 \% \mathrm{Ti}, 6 \% \mathrm{Al}$ and $4 \% \mathrm{~V}$. The concentrations determined by ICP OES, especially for Ti, suffered some fluctuation, 
which is explained by the high dilution factor of the solutions adopted for avoiding saturation of the detector. However, in general, results were coherent with nominal concentrations of the alloys.

\section{WDXRF determination}

Figure 1 shows the spectra obtained for qualitative analysis of the three major constituents and $\mathrm{Fe}$, as already anticipated by ICP OES, no other minor constituent was found.

All nine samples are represented by a different line in each spectrum fragment. It is possible to see the homogeneity of the samples, all nine samples contained about the same of the major constituent elements ( $\mathrm{Ti}, \mathrm{Al}$ and V) with RSD (relative standard deviation) values ranging from $0.2 \%$ (for $\mathrm{Ti}$ ) to $1.2 \%$ (for $\mathrm{Al}$ ), but for $\mathrm{Fe}$ signals five samples had signal intensities 2-fold higher than the others, indicating they have a higher concentration of $\mathrm{Fe}$, and the overall RSD value was $25 \%$.

This technique suffers from interferences caused by adjacent elements, such as Ti and V. To compensate these
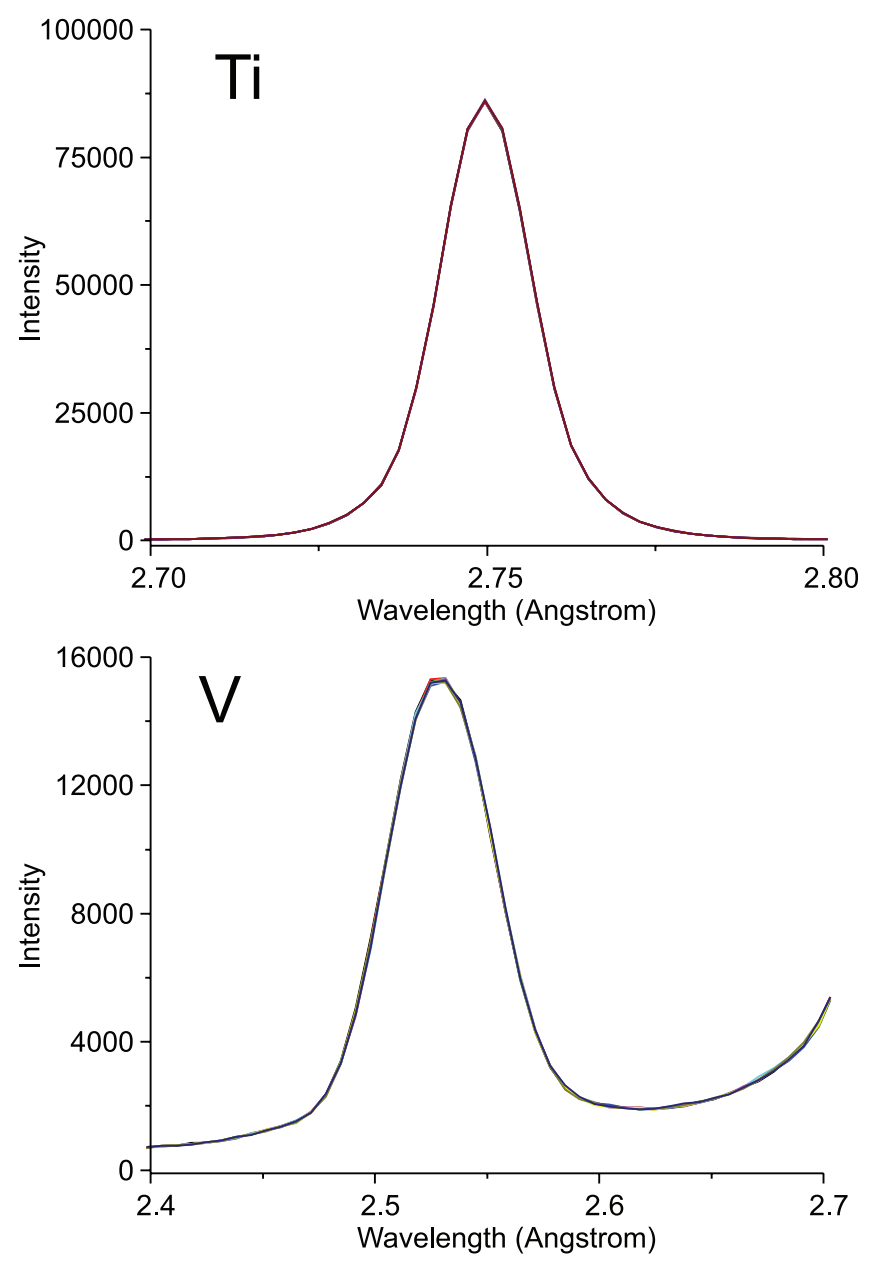

Figure 1. Spectrum fragment of Ti, Al, V and Fe acquired by WDXRF. interferences, the wavelength increments of the $\mathrm{V}$ were reduced to $0.025 \AA$, so only the region of the $\mathrm{V}$ signal would be analyzed. Even with the decrease of increments, it was possible to see that $\mathrm{V}$ spectrum started to loose linearity again after $2.7 \AA$, because of the interference caused by Ti.

The concentrations calculated using the software Uniquant $^{\circledR}$ are shown in Table 4.

Samples 4, 6, 8 and 9 had Fe concentrations about half lower than the other samples, confirming the spectra acquired by aiming qualitative analysis (see Figure 1). This same trend was observed for ICP OES determinations (see Table 3).

The concentrations of $\mathrm{Ti}$ and $\mathrm{V}$ were coherent with nominal concentrations ( $\mathrm{Ti} 90 \%$ and $\mathrm{V} \mathrm{4 \%}$ ) and those obtained by ICP OES (see Table 3), but the concentrations of $\mathrm{Al}$ were systematically $2 \%$ lower (the studied Ti alloys are supposed to contain around $6 \%$ of $\mathrm{Al}$ ), even when compared with ICP OES results (Table 3). This effect is not clear since the software automatically corrects for interferences.
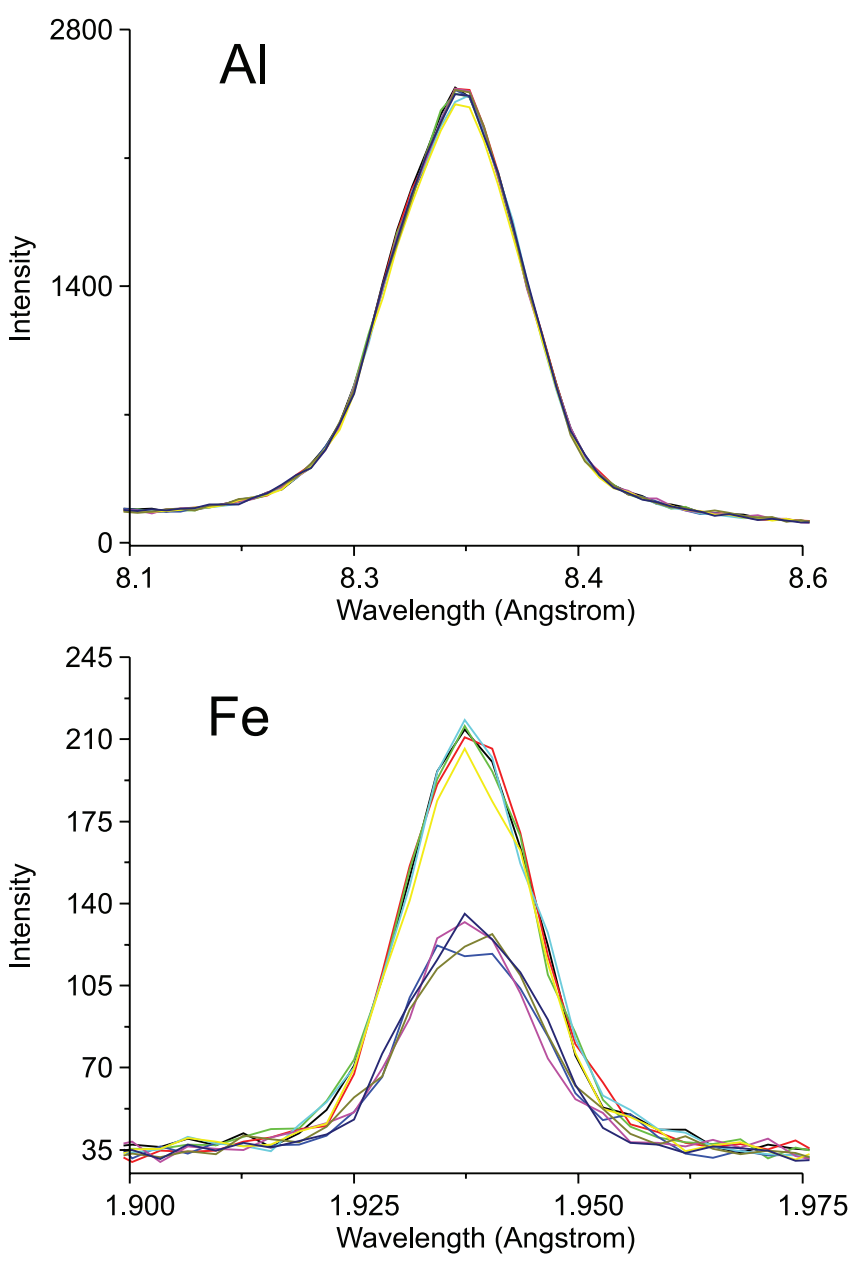
Table 4. Concentrations (mean \pm standard deviation, $\mathrm{n}=3$ ) determined by WDXRF using the software Uniquant ${ }^{\circledR}$

\begin{tabular}{lcccc}
\hline \multirow{2}{*}{ Sample } & \multicolumn{4}{c}{ Concentration / } \\
\cline { 2 - 5 } & $\mathrm{Ti}$ & $\mathrm{Al}$ & $\mathrm{V}$ & $\mathrm{Fe}$ \\
\hline 1 & $89.3 \pm 0.2$ & $4.0 \pm 0.1$ & $4.4 \pm 0.1$ & $0.22 \pm 0.02$ \\
2 & $89.8 \pm 0.2$ & $4.0 \pm 0.1$ & $4.5 \pm 0.1$ & $0.24 \pm 0.02$ \\
3 & $89.8 \pm 0.2$ & $4.1 \pm 0.1$ & $4.3 \pm 0.1$ & $0.21 \pm 0.02$ \\
4 & $89.9 \pm 0.2$ & $4.2 \pm 0.1$ & $4.3 \pm 0.1$ & $0.14 \pm 0.02$ \\
5 & $89.7 \pm 0.2$ & $4.2 \pm 0.1$ & $4.3 \pm 0.1$ & $0.23 \pm 0.02$ \\
6 & $90.0 \pm 0.2$ & $4.3 \pm 0.1$ & $4.2 \pm 0.1$ & $0.08 \pm 0.01$ \\
7 & $90.0 \pm 0.2$ & $4.1 \pm 0.1$ & $4.3 \pm 0.1$ & $0.20 \pm 0.02$ \\
8 & $89.9 \pm 0.2$ & $4.1 \pm 0.1$ & $4.2 \pm 0.1$ & $0.11 \pm 0.02$ \\
9 & $89.7 \pm 0.2$ & $4.3 \pm 0.1$ & $4.2 \pm 0.1$ & $0.12 \pm 0.02$ \\
\hline
\end{tabular}

WDXRF: wavelength dispersive $\mathrm{X}$-ray fluorescence.

The software also makes normalizations, such as the summation of concentrations is $100 \%$, which interfere with results, especially because some elements eventually present, such as $\mathrm{Na}$ and $\mathrm{K}$, are detected and counted in the normalization. In the experiment, about $0.3 \%$ of the total was $\mathrm{Na}$ and $\mathrm{K}$ and this is a source of error.

Also, the concentrations obtained by ICP OES analysis (see Table 3) as reference values were used to test the quantification of the signals shown in Figure 1. In this case, 5 and 4 samples were selected to establish a calibration model and to validate it, respectively. Table 5 shows the trueness when comparing the values obtained by WDXRF with the ones by ICP OES.

The SEC (standard error of calibration) varied from 0.01

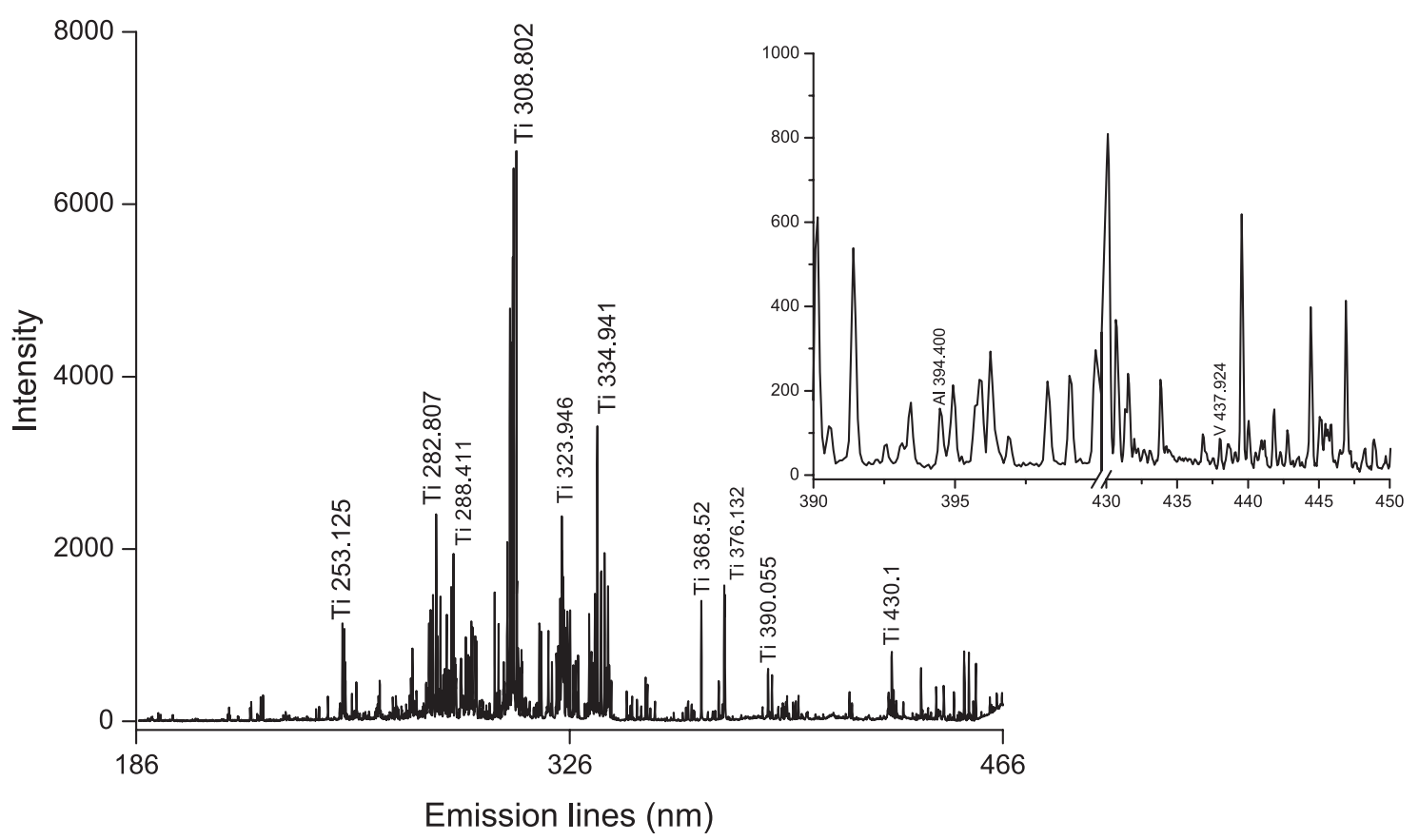

Table 5. Trueness of the comparison between concentrations obtained by ICP OES and WDXRF

\begin{tabular}{lcccc}
\hline \multirow{2}{*}{ Sample } & \multicolumn{4}{c}{ Trueness comparing ICP OES and WDXRF / \% } \\
\cline { 2 - 5 } & $\mathrm{Ti}$ & $\mathrm{Al}$ & $\mathrm{V}$ & $\mathrm{Fe}$ \\
\hline 1 & 105 & 111 & 96 & 105 \\
2 & 101 & 102 & 100 & 103 \\
3 & 84 & 87 & 88 & 102 \\
4 & 97 & 101 & 93 & 112 \\
5 & 103 & 108 & 88 & 101 \\
6 & 101 & 111 & 114 & 103 \\
7 & 97 & 99 & 98 & 94 \\
8 & 99 & 108 & 96 & 102 \\
9 & 118 & 108 & 111 & 89 \\
\hline
\end{tabular}

ICP OES: inductively coupled plasma optical emission spectrometry; WDXRF: wavelength dispersive X-ray fluorescence.

to $0.5 \%$ for $\mathrm{Al}, \mathrm{V}$ and $\mathrm{Fe}$ and $12 \%$ for Ti. The overall RSDs varied from 11 to $14 \%$ for the three major constituents and $29 \%$ for $\mathrm{Fe}$, probably because of broad concentration range.

Iron was present in low concentrations (lower than $0.3 \%$ ) being coherent with signal intensities and concentrations determined by ICP OES, that were also below $0.3 \%$.

\section{Laser techniques}

\section{LIBS}

\section{Optimization}

After evaluating experimental conditions, the adopted instrumental parameters were: laser pulse energy of $80 \mathrm{~mJ}$, 
delay time of $0.5 \mu$ and spot size of $150 \mu \mathrm{m}$. Analysis was made in raster mode and 100 spectra of each sample were acquired. Castro and Pereira-Filho ${ }^{12}$ used in their studies the Doehlert design to adjust the 3 parameters (laser pulse energy, spot size and delay time). This tool allows the study of the variables in different levels simultaneously ${ }^{26}$ proving to be useful and effective.

Laser pulse energy, delay time and spot size were assessed by Doehlert design. High laser pulse energy and low delay time were required for all the 3 elements simultaneously ( $\mathrm{Ti}, \mathrm{Al}$ and $\mathrm{V}$ ). Spot size was important only for $\mathrm{V}$, requiring a high value. This could be explained by the relatively low concentration of $\mathrm{V}$ in the samples ( $4 \%$ as nominal value), therefore, with a higher spot size less interference from other emission lines is observed.

Due to the high concentration of $\mathrm{Ti}$, it was necessary to establish a compromise condition for the parameters (laser pulse energy, delay time and spot size) to decrease its signal, otherwise it would saturate the detector. This affected all three elements, decreasing their signals.

Doehlert design proved to be helpful as well, saving time and experiments, creating models that made possible to see the effect of the three variables on the signals height and area simultaneously. ${ }^{22}$

\section{LIBS: application for orthopedic alloys}

Figure 2 shows a typical spectrum obtained with the most intense emission lines of $\mathrm{Ti}, \mathrm{Al}$ and $\mathrm{V}$ highlighted.

The software Aurora ${ }^{\circledR}$ (Applied Spectra) was used to identify prominent emission lines. It is possible to see several lines of Ti, including some very intense, such as the lines I $334.9 \mathrm{~nm}$ and II $308.8 \mathrm{~nm}$, and some less intense, such as the lines I 430.1 and II $390.0 \mathrm{~nm}$.

The spectrum is populated with hundreds of $\mathrm{Ti}$ emission lines, and few lines of $\mathrm{Al}$, and $\mathrm{V}$ were identified. Iron was not identified using LIBS. Several Al, $\mathrm{V}$ and $\mathrm{Fe}$ emission lines were lower than the respective background noise, making it impossible to find. It could be explained by the relative poor sensitivity ${ }^{24}$ of the LIBS technique, not being able to detect high and low concentrations elements using a single experimental condition. This is a drawback that must be overcome with the optimization method for samples containing one element with notably higher concentration compared to the other constituents, such as the samples in this study (i.e., ca. $90 \%$ of Ti). The optimization needs to simultaneously decrease the signal of the most intense element and enhance the signals of the lower constituents for simple and fast multi-elemental analyses. The LIBS measurements were not effective in this study.

\section{LA-ICP-MS}

\section{Optimization}

The optimal condition for ablation was 525 and $375 \mathrm{~mL} \mathrm{~min}^{-1}$ for He and Ar flow rate, respectively, $50 \mu \mathrm{m}$ for spot size, $5 \mathrm{~Hz}$ for frequency, $80 \%$ for laser pulse energy and $20 \mu \mathrm{m} \mathrm{s}^{-1}$ for speed. The ablation was made in a single line, lasting $180 \mathrm{~s}$. For optimization, the fractional design was chosen due to the higher number of variables (6 in total), ${ }^{27}$ making it preferable than the Doehlert design. This optimization showed to be efficient, generating regression models demonstrating simultaneously the influence of each variable.

\section{Signals evaluation}

In this experiment, it was monitored signals for 43 isotopes. However, based on ICP OES data, it was observed that in addition to the major constituents, only Fe was detected in the samples. Thus, only these elements were considered. Figure 3 shows the profile of 6 mass-to-charge ratio signals along the analysis time.

It is possible to observe signals for the three major elements and $\mathrm{Fe}$, showing an improvement in sensitivity compared to the LIBS technique. As expected, the ${ }^{48} \mathrm{Ti}$ had the most intense signal, followed by ${ }^{27} \mathrm{Al}$. This is explained by the fact that the concentration of Ti were much higher (90\%) than the other elements, also the ${ }^{48} \mathrm{Ti}$ has an abundance of $73.8 \%$. The ${ }^{27} \mathrm{Al}$ is the only stable isotope and the second most concentrated element $(6 \%)$. The qualitative analysis of these intense signals is coherent with their nominal concentration $(90 \% \mathrm{Ti}, 6 \% \mathrm{Al}$ and $4 \% \mathrm{~V})$.

The other Ti isotopes $\left({ }^{50} \mathrm{Ti},{ }^{49} \mathrm{Ti},{ }^{47} \mathrm{Ti}\right.$ and ${ }^{46} \mathrm{Ti}$, data not shown) vary from 5 to $7 \%$ of abundance. The ${ }^{51} \mathrm{~V}$ has an abundance of $99.75 \%$ and had intensity 10 -fold lower when compared with $\mathrm{Ti}$ isotopes. The ${ }^{56} \mathrm{Fe}$ had a low signal intensity since it is a contaminant element in this alloy. The $\mathrm{C}$, even though it is not supposed to be present in the sample, was monitored as residual carbon. It is important to monitor $\mathrm{C}$ to make normalizations, reducing fluctuations due to hotspots and sample microheterogeneity.

Concentration correlations combining ICP OES data and laser based techniques signals

The next step was to combine the reference concentrations obtained by ICP OES after microwaveassisted digestion (see Table 3), the emission signals from LIBS and $\mathrm{m} / z$ counts from LA-ICP-MS, in order to quantify the major constituents.

These correlations were not successful, probably because all samples were too similar in concentrations, 

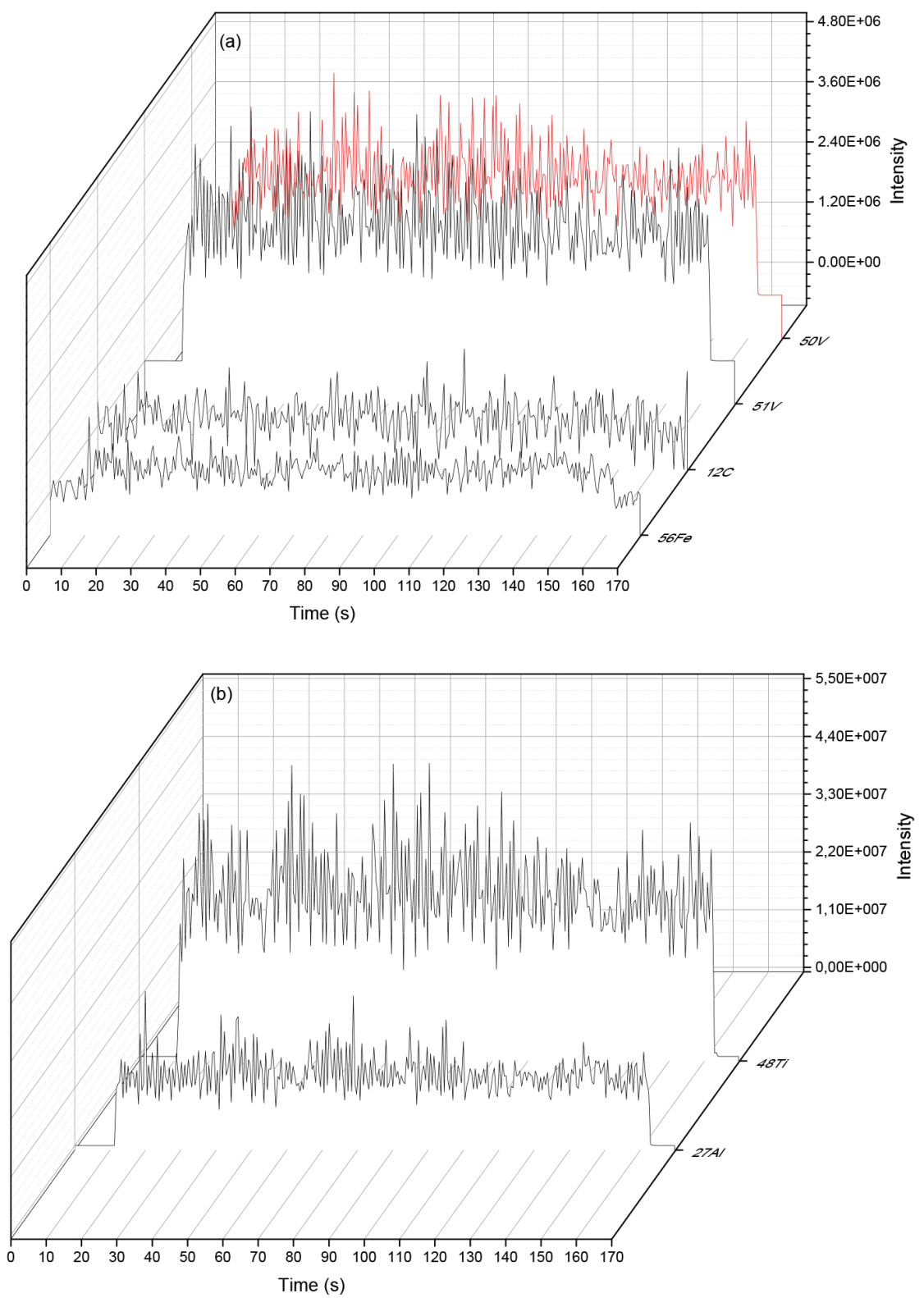

Figure 3. Mass-to-charge ratio for (a) ${ }^{56} \mathrm{Fe},{ }^{12} \mathrm{C},{ }^{51} \mathrm{~V}$ and ${ }^{50} \mathrm{~V}$ and (b) ${ }^{27} \mathrm{Al}$ and ${ }^{48} \mathrm{Ti}$ monitored with LA-ICP-MS with their intensities along time.

not providing a suitable linear dynamic range correlation. Also, normalizations were done to correct any variations of the signal. For LIBS, 12 normalizations strategies ${ }^{12}$ were applied and for LA, the signals of the ${ }^{12} \mathrm{C}$ and ${ }^{13} \mathrm{C}$ were used to correct them, but none of these normalizations helped with the linearity of the correlation. Additional studies are needed to investigate the potential of these techniques to quantify analytes when sample masses in $\mu$ g range is ablated.

\section{Conclusions}

The two laser techniques were useful in qualitative analysis of Ti alloys. LIBS had a lower sensitivity than expected, probably due to the decrease in overall sensitivity for avoiding saturation of the detector with Ti signals. In addition, the LIBS spectra was populated with hundred $\mathrm{Ti}$ emission lines, jeopardizing the $\mathrm{Al}$ and $\mathrm{V}$ lines identification. As expected, LA-ICP-MS was more sensitive, making feasible the identification of less concentrated elements, such as $\mathrm{V}$ and Fe.

The results obtained by microwave-assisted digestion of samples followed by determination using ICP OES was in agreement with nominal concentrations despite being affected by fluctuations due to the high dilutions needed. Although the Ti alloy studied is highly resistant to chemical attack, microwave-assisted digestion was relatively simple, using only $25 \% \mathrm{v} / \mathrm{v} \mathrm{H}_{2} \mathrm{SO}_{4}$, which is attractive as 
a procedure for routine analysis.

The WDXRF method was easily applied and no sample preparation was required. Sensitivity was enough to detect all elements, even Fe present as a contaminant of the alloy. The build-in software was efficient to quantify components of the alloy and only Al concentrations were slightly lower than expected, but the main feature of the software is the ability to scan the alloy for all constituents and to provide at least a semi-quantitative estimation of their concentrations. This analytical capability is especially appealing for screening and preliminary studies.

\section{Acknowledgments}

This study was supported by the São Paulo Research Foundation (FAPESP), 2016/01513-0, 2014/22408-4 (MSc) and 2016/17221-8 (PhD) grants to J. P. C. and the Conselho Nacional de Desenvolvimento Científico e Tecnológico (CNPq, 401074/2014-5, 443771/2014-6 and $305637 / 2015-0)$. The authors are grateful to Analítica, Berghof, Thermo Scientific and CETAC for instrument loans (ICP OES, LA-ICP-MS, and microwave oven) and technical support.

\section{References}

1. Geetha, M.; Singh, A. K.; Asokamani, R.; Gogia, A. K.; Mater. Sci. 2009, 54, 397.

2. Athanasiou, K. A.; Niederauer, G. G.; Agrawal, C. C.; Biomaterials 1996, 17, 93.

3. Agência Nacional de Vigilância Sanitária; Cirurgias com Implantes/Próteses: Critérios Nacionais de Infecções Relacionadas à Assistência à Saúde, Brasília, 2011. Available at https://www20.anvisa.gov.br/segurancadopaciente/images/ documentos/cs_manual_criteriosNacionais_implantes_ proteses.pdf, accessed in October 2017.

4. Long, M.; Rack, H. J.; Mater. Sci. Eng. 2005, 25, 382.

5. ASTM F136-13: Standard Specification for Wrought Titanium6Aluminum-4Vanadium ELI (Extra Low Interstitial) Alloy for Surgical Implant Applications (UNS R56401), ASTM International, West Conshohocken, PA, 2013. Performance Titanium Group ${ }^{\circledR}$ (PTG), available at https://performacetitanium. com/astm-f136, accessed in October 2017.

6. Kuroda, D.; Niinomi, M.; Morinaga, M.; Kato, Y.; Yashiro, T.; Mater. Sci. Eng., A 1998, 243, 244.
7. Zatta, P.; Drago, D.; Bolognin, S.; Sensi, S. L.; Trends Pharmacol. Sci. 2009, 30, 346.

8. Rokosz, K.; Hryniewicz, T.; Raaen, S.; Int. J. Adv. Manuf. Technol. 2016, 85, 2425.

9. Pasquini, C.; Cortez, J.; Silva, L. M. C.; Gonzaga, F. B.; J. Braz. Chem. Soc. 2007, 18, 463.

10. Gonzaga, F. B.; Pasquini, C.; Spectrochim. Acta, Part B 2008, $63,56$.

11. Günther, D.; Hattendorf, B.; TrAC, Trends Anal. Chem. 2005, $24,255$.

12. Castro, J. P.; Pereira-Filho, E. R.; J. Anal. At. Spectrom. 2016, $31,2005$.

13. Ni, Z.; Chen, X.; Fu, H.; Wang, J.; Dong, F.; Front. Phys. 2014, 9, 439.

14. Valenzuela, A.; Munson, C.; Porwitzky, A.; Weidman, M.; Richardson, M.; Appl. Phys. B 2014, 116, 485.

15. Sajnóg, A.; Hanc, A.; Makuch, K.; Koczorowski, R.; Barlkiewicz, D.; Spectrochim. Acta, Part B 2016, 125, 1.

16. Sakar, A.; Mao, X.; Russo, R. E.; Spectrochim. Acta, Part B 2014, 92, 42.

17. Anjos, M. J.; Lopes, R. T.; Jesus, E. F. O.; Simabuco, S. M.; Cesareo, R.; X-Ray Spectrom. 2002, 31, 120.

18. Vazquez, C.; Barbaro, N.; Lopez, S.; X-Ray Spectrom. 2003, $32,57$.

19. Velmer, A. F.; Richard, N. K.; Anal. Chem. 1974, 46, 1110 A.

20. Sperança, M. A.; Aquino, F. W. B.; Fernandes, M. A.; LopezCastillo, A.; Carneiro, R. L.; Pereira-Filho, E. R.; Geostand. Geoanal. Res. 2017, 41, 273.

21. Andrade, D. F.; Pereira-Filho, E. R.; Konieczynski, P.; J. Braz. Chem. Soc. 2017, 28, 838.

22. Ferreira, S. L. C.; Santos, W. N. L.; Quintella, C. M.; Barros Neto, B.; Bosque-Sendra, J. M.; Talanta 2004, 63, 1061.

23. MATLAB, The MathWorks, Natick, USA, 2009.

24. Yong, C.; Rare Met. Mater. Eng. 2012, 10, 1871.

25. Fernando, V. S.; Trevizan, L. C.; Silva, C. S.; Nogueira, A. R. A.; Nóbrega, J. A.; Spectrochim. Acta, Part B 2002, 57, 1905.

26. Fichet, P.; Tabarant, M.; Salle, B.; Anal. Bioanal. Chem. 2006, 385,338 .

27. Youssef, A.; Beauchamp, Y.; Thomas, M.; Comput. Ind. Eng. 1994, 27, 59 .

Submitted: June 1, 2017

Published online: October 10, 2017 